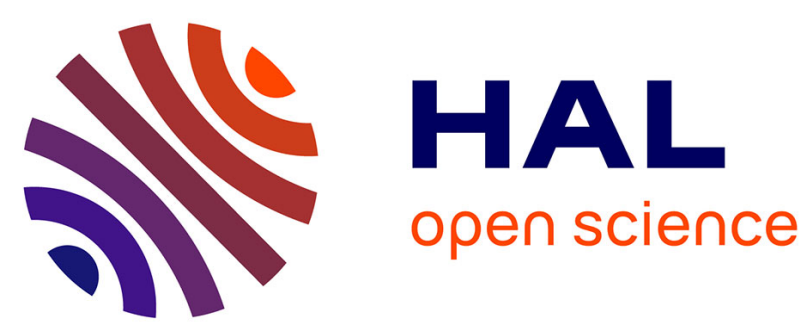

\title{
Integrated broadband mid-infrared polarization insensitive Fourier-Transform spectrometer
}

\author{
Qiankun Liu, Joan Manel Ramírez, Vladyslav Vakarin, Xavier Le Roux, \\ Carlos Alonso-Ramos, Jacopo Frigerio, Andrea Ballabio, Enrico Talamas \\ Simola, David Bouville, Laurent Vivien, et al.
}

\section{To cite this version:}

Qiankun Liu, Joan Manel Ramírez, Vladyslav Vakarin, Xavier Le Roux, Carlos Alonso-Ramos, et al.. Integrated broadband mid-infrared polarization insensitive Fourier-Transform spectrometer. 2018 Asia Communications and Photonics Conference (ACP), Oct 2018, Hangzhou, France. pp.1-3, 10.1109/ACP.2018.8595940 . hal-02362449

\section{HAL Id: hal-02362449 \\ https://hal.science/hal-02362449}

Submitted on 13 Nov 2019

HAL is a multi-disciplinary open access archive for the deposit and dissemination of scientific research documents, whether they are published or not. The documents may come from teaching and research institutions in France or abroad, or from public or private research centers.
L'archive ouverte pluridisciplinaire HAL, est destinée au dépôt et à la diffusion de documents scientifiques de niveau recherche, publiés ou non, émanant des établissements d'enseignement et de recherche français ou étrangers, des laboratoires publics ou privés. 


\section{Integrated broadband mid-infrared polarization insensitive Fourier-Transform spectrometer}

\author{
Qiankun Liu \\ C2N/Univ Paris Sud/CNRS \\ Orsay, France \\ qiankun.liu@u-psud.fr \\ Xavier Le Roux \\ C2N/Univ Paris Sud/CNRS \\ Orsay, France \\ xavier.leroux@u-psud.fr \\ Andrea Ballabio \\ Politechnico Milano \\ Como, Italy \\ andrea.ballabio@polimi.it \\ Laurent Vivien \\ C2N/Univ Paris Sud/CNRS \\ Orsay, France \\ laurent.vivien@u-psud.fr
}

\author{
Joan Manel Ramírez \\ C2N/Univ Paris Sud/CNRS \\ Orsay, France \\ joan-manel.ramirez@u-psud.fr \\ Carlos Alonso-Ramos \\ C2N/Univ Paris Sud/CNRS \\ Orsay, France \\ carlos.ramos@u-psud.fr \\ Enrico Talamas Simola \\ Politechnico Milano \\ Como, Italy \\ enrico.talamas@polimi.it \\ Giovanni Isella
Politechnico Milano
Como, Italy
ovanni.isella@ polimi.it
}

\author{
Vladyslav Vakarin \\ C2N/Univ Paris Sud/CNRS \\ Orsay, France \\ vladyslav.vakarin@u-psud.fr \\ Jacopo Frigerio \\ Politechnico Milano \\ Como, Italy \\ jacopo.frigerio@polimi.it \\ David Bouville \\ C2N/Univ Paris Sud/CNRS \\ Orsay, France \\ david.bouville@u-psud.fr \\ Delphine Marris-Morini \\ C2N/Univ Paris Sud/CNRS \\ Orsay, France \\ delphine.morini@u-psud.fr
}

\begin{abstract}
Due to the rotational and vibrational frequency, molecules show unique absorption spectrum in the mid-infrared fingerprint region from 500 to $1500 \mathrm{~cm}^{-1}$. Hence, the demonstration of integrated on-chip spectrometers with compact sizes, cost-effective and high performance is important. Here, we demonstrate the first polarization insensitive broadband operational mid infrared spatial heterodyne Fourier-Transform spectrometer (SHFTS) working beyond $5 \mu \mathrm{m}$ wavelength. A resolution better than $15 \mathrm{~cm}^{-1}$ for both TE/TM polarizations has been experimentally demonstrated in an unprecedented bandwidth of $800 \mathrm{~cm}^{-1}$ (from $5 \mu \mathrm{m}$ to $8.5 \mu \mathrm{m}$ wavelength) for our integrated on-chip SHFTS, using a graded-index Ge-rich SiGe photonics platform.
\end{abstract}

Keywords-Mid infrared, Fourier Transform spectroscopy, silicon photonics, graded-index SiGe.

\section{INTRODUCTION}

Due to the unique rotational and vibrational frequency of molecules in the mid infrared fingerprint region, which ranges from $500 \mathrm{~cm}^{-1}$ to $1500 \mathrm{~cm}^{-1}$. The demonstration of miniaturized on-chip spectroscopic systems with low power consumption and high performance in the mid infrared, for multi target detection would have a great potential for many applications, such as medical diagnosis [1], chemical and biological sensing [2] or security [3], and many others. Photonic integration based on planar waveguide technology offers unique perspective towards compact sizes, low power consumption and high performance spectrometers. In the last years, using silicon photonics technologies, different approaches have been developed for the demonstration of integrated on-chip spectroscopic systems, such as arrayed waveguide gratings [4], echelle gratings [5] and Fourier-Transform spectrometers
(FTS) [6-9]. Nowadays, many researchers have studied already the FTS based on the silicon-on-insulator (SOI) platform working in the near infrared (NIR) $[6,7,9]$ and short-wave infrared (SWIR) wavelength range [8]. Integrated spatial heterodyne Fourier-Transform spectrometer (SHFTS) with multi-aperture benefits from the high optical throughput, high spectral resolution, and relaxed fabrication tolerances using a phase and amplitude correction algorithms. SHFTS is typically based on an array of Mach-Zehnder interferometers (MZIs) with linearly increasing path length differences. Recently, an increasing number of research groups is paying attention on the development of photonic circuits operational in the mid infrared wavelength range beyond $5 \mu \mathrm{m}$ [10-15]. However, it is still a shortage in the development of integrated on-chip spectroscopic system covering the wide mid-infrared fingerprint region. Meanwhile, in all cases in the literature of FTS, their operation is limited to single polarization because of the birefringence of the waveguides, while wideband polarization insensitive on-chip spectrometers are highly desirable. Most recently, the experimental demonstration of low-loss broadband mid-infrared waveguides [16] and interferometers [17], based on Ge-rich SiGe platform, provides a promising departing point for the development of new spectroscopic system in the mid infrared range.

In this work, a polarization insensitive mid-infrared ultra wideband SHFTS have been firstly experimentally demonstrated based on the Ge-rich SiGe platform. The proposed SHFTS is working between $5 \mu \mathrm{m}\left(2000 \mathrm{~cm}^{-1}\right)$ and $8.5 \mu \mathrm{m}\left(\sim 1170 \mathrm{~cm}^{-1}\right)$ wavelength, with a resolution better than $15 \mathrm{~cm}^{-1}$ both in TE and TM polarizations. The waveguide engineering provides low birefringence and low dispersion in 
the interesting wavelength range, which allows the broadband operation.

\section{DEVICE DESIGN AND RESULTS}

The fabricated on-chip SHFTS is based on 19 MZIs with linearly increasing path lengths as shown in Fig 1. Fabrication details can be found in [16]. The used beam splitters/combiners in the MZIs are multimode interferometer (MMI), optimized for the broadband operation both in TE/TM polarizations in the 5 to $8.5 \mu \mathrm{m}$ wavelength range. The SEM image of used MMI is shown in the inset of Fig 1 . With a maximum path length difference of $\Delta L_{\max }=178.6 \mu \mathrm{m}$ and $N=19$, taking into account the group index of 4.04 , a theoretical resolution of $13.8 \mathrm{~cm}^{-1}$ and a FSR of $132 \mathrm{~cm}^{-1}$ is obtained.

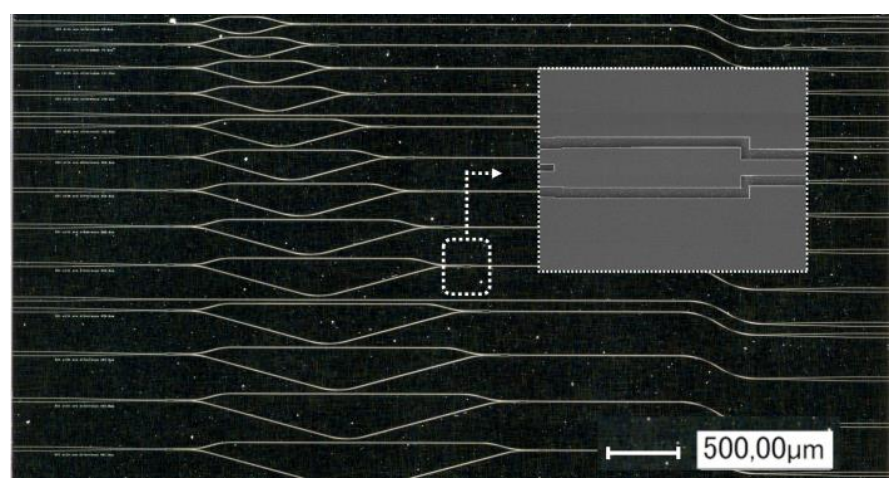

Fig. 1. Optical microscope image of a part of the MIR Fourier-Transform spectrometer, (inset) SEM image of a multimode interferometer.

To confirm the good operation of proposed SHFTS, the reconstruction of a monochromatic signal has been performed at different wavelengths scanned along the full operation range from 5 to $8.5 \mu \mathrm{m}$, using a transformation matrix retrieval algorithm [6]. By applying this retrieval algorithm, the phase and amplitude errors caused by the fabrication imperfection could be effectively corrected. With this method, the spectrum is retrieved by applying the multiplication of the interferogram of the input signal recorded from the output of each MZI, and the pseudo-inverse of the calibration matrix $T$ containing the transmittance of each 19 MZIs. The spatial interferogram of the SHFTS is obtained by recording independently the transmission of each MZI. The set-up is described in detail in [16]. Data processing is applied to remove imperfections from the raw measurements, as the frequency dependence of the laser power. Firstly, the transmission of MZIs is normalized by the straight waveguide transmission, then a subtraction of mean value of the transmittance is performed. Finally, the interferogram is obtained by a division of the envelop wavefunction of the previous transmittance. This data treatment has been applied both to TE and TM polarizations. The normalized transmittance spectrum of each 19 MZIs for TE polarization, which is between -1 and 1, is shown in Fig 2 . Interestingly, the reported interferogram of the MZIs shows quite good alignment without any supernumerary phase correction in the data treatment process. As the Littrow frequency, where all MZIs have a maximum transmittance, for frequencies of 1185,1450 and $1715 \mathrm{~cm}^{-1}$ could be clearly observed. This could be a clear evidence of low phase distortion which is typically produced by the fabrication errors, and therefore a direct proof of the robustness of the Ge-rich $\mathrm{SiGe}$ waveguides to the fabrication imperfections.

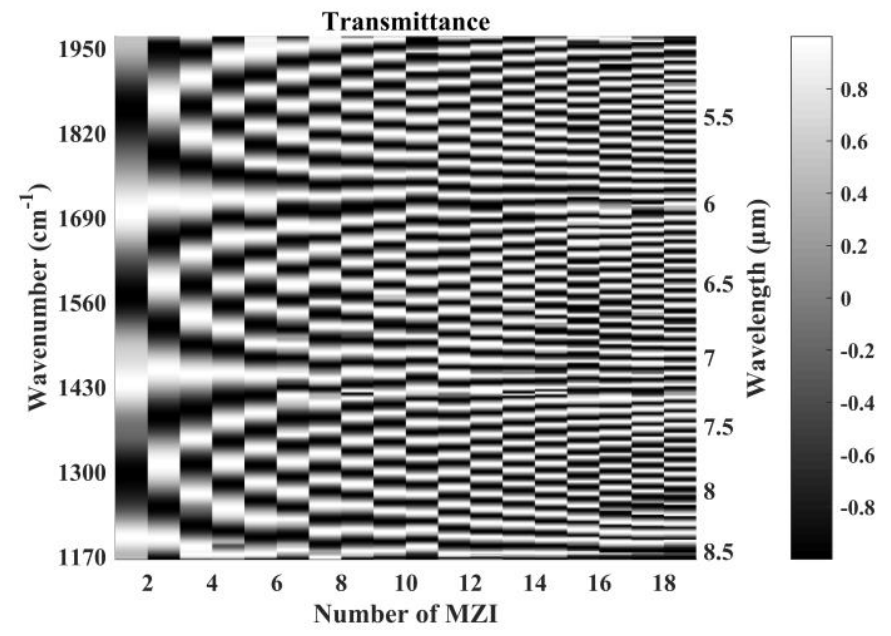

Fig. 2. Experimental transmittance of each 19 MZIs for the fundamental transverse electric (TE) mode in the interferometer array of the spectrometer.

The proposed Ge-rich SiGe SHFTS allows for spectral retrieval of monochromatic input signals in an unprecedented bandwidth of $800 \mathrm{~cm}^{-1}$ centered at $1560 \mathrm{~cm}^{-1}$. Note that, a retrieval range narrower than the device FSR of $132 \mathrm{~cm}^{-1}$ has been considered at each input frequency, and a Gaussian apodization function in the retrieval window has been performed to reduce the sidelobe [18]. Then the spectra resolution is obtained by measuring the full-width at half maximum (FWHM) of the retrieved spectrum. An average resolution of $12 \mathrm{~cm}^{-1}$ and $14.5 \mathrm{~cm}^{-1}$ has been obtained for TE and TM polarizations respectively. Fig 3 shows an example of the experimentally retrieved monochromatic spectrum at $1817 \mathrm{~cm}^{-1}$ with a spectra resolution of $13.2 \mathrm{~cm}^{-1}$ in TE polarization.

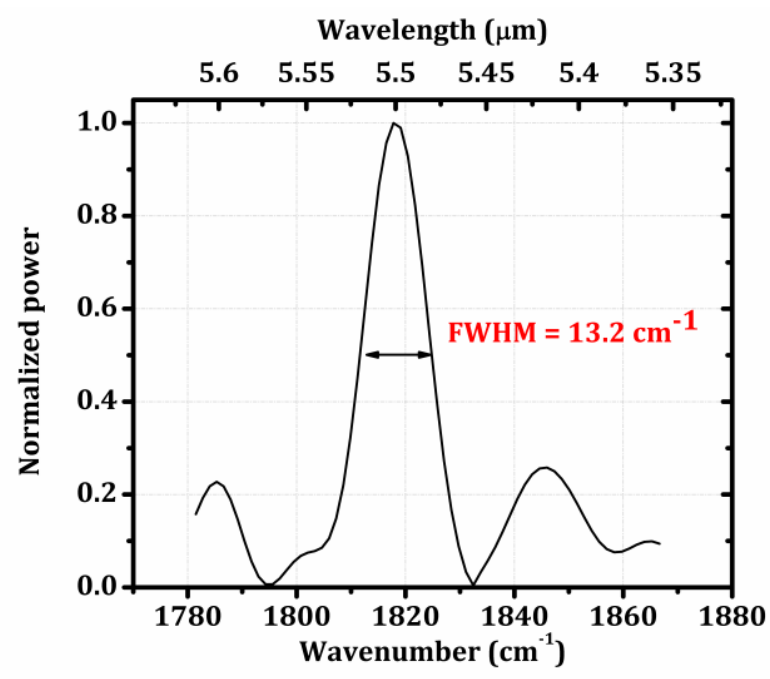

Fig. 3. Experimentally retrieved spectrum for a monochromatic input at $1817 \mathrm{~cm}^{-1}$ with a FWHM of $13.2 \mathrm{~cm}^{-1}$ in TE polarization. 


\section{CONCLUSION}

As a conclusion, a SHFTS based on graded-index Ge-rich SiGe platform, working both in TE and TM polarizations has been reported. An unprecedented broadband operation of $800 \mathrm{~cm}^{-1}$, a FSR of $132 \mathrm{~cm}^{-1}$ and a resolution below $15 \mathrm{~cm}^{-1}$ are obtained for the studied wavelength range from $5 \mu \mathrm{m}$ $\left(2000 \mathrm{~cm}^{-1}\right)$ to $8.5 \mu \mathrm{m}\left(1170 \mathrm{~cm}^{-1}\right)$. Low phase errors have been demonstrated, indicating a good robustness of waveguide design and relaxed fabrication tolerances. The device resolution can be seamlessly designed by integrating more Mach Zehnder interferometers or by changing the path length differences. These results pave the way for future demonstration of robust, high resolution and cost effective multi-target on-chip spectrometers in the wideband mid infrared fingerprint wavelength region.

\section{ACKNOWLEDGMENT}

The project is financially supported by the European Research Council (ERC) under the European Union's Horizon 2020 research and innovation program ( $\left.{ }^{\circ} 639107-I N s P I R E\right)$. The fabrication of the device was performed at the Plateforme de Micro-Nano-Technologie/C2N, which is partially funded by the "Conseil Général de l'Essonne". This work was partly supported by the French RENATECH network.

\section{REFERENCES}

1. S. Rehman, Z. Movasaghi, J. A. Darr, and I. U. Rehman, Appl. Spectrosc. Rev. 45, 355 (2010).

2. Q. Liu, J. M. Ramirez, V. Vakarin, X. Le Roux, A. Ballabio, J. Frigerio, D. Chrastina, G. Isella, D. Bouville, L. Vivien, C. A. Ramos, and D. MarrisMorini, Opt. Mater. Express 8, 1305 (2018).

3. Y. C. Chang, P. Wägli, V. Paeder, A. Homsy, L. Hvozdara, P. Van Der Wal, J. Di Francesco, N. F. De Rooij, and H. Peter Herzig, Lab Chip 12, 3020 (2012).

4. A. Vasiliev, M. Muneeb, J. Allaert, J. Van Campenhout, R. Baets, and G.
Roelkens, IEEE J. Sel. Top. Quantum Electron. 24, (2018).

5. X. Ma, M. Li, and J. J. He, IEEE Photonics J. 5, (2013).

6. A. V. Velasco, P. Cheben, P. J. Bock, A. Delâge, J. H. Schmid, J. Lapointe, S. Janz, M. L. Calvo, D.-X. Xu, M. Florjańczyk, and M. Vachon, Opt. Lett. 38, 706 (2013).

7. D. M. Kita, B. Miranda, D. Favela, D. Bono, J. Michon, H. Lin, T. Gu, and J. Hu, (2018).

8. M. Nedeljkovic, A. V. Velasco, A. Z. Khokhar, A. Delage, P. Cheben, and G. Z. Mashanovich, IEEE Photonics Technol. Lett. 28, 528 (2016).

9. H. Podmore, A. Scott, P. Cheben, A. Velasco, J. Schmid, M. Vachon, and R. Lee, 42, 1440 (2017).

10. M. G. Hansen, I. Ernsting, S. V. Vasilyev, A. Grisard, E. Lallier, B. Gérard, and S. Schiller, Opt. Express 21, 27043 (2013).

11. C. Gilles, L. J. Orbe, G. Carpintero, G. Maisons, and M. Carras, Opt. Express 23, 20288 (2015).

12. H. Lin, L. Li, Y. Zou, S. Danto, J. D. Musgraves, K. Richardson, S. Kozacik, M. Murakowski, D. Prather, P. T. Lin, V. Singh, A. Agarwal, L. C. Kimerling, and J. Hu, Opt. Lett. 38, 1470 (2013).

13. A. Gutierrez-Arroyo, E. Baudet, L. Bodiou, J. Lemaitre, I. Hardy, F. Faijan, B. Bureau, V. Nazabal, and J. Charrier, Opt. Express 24, 23109 (2016).

14. J. S. Penadés, A. Sánchez-Postigo, M. Nedeljkovic, A. Ortega-Moñux, J. G. Wangüemert-Pérez, Y. Xu, R. Halir, Z. Qu, A. Z. Khokhar, A. Osman, W. Cao, C. G. Littlejohns, P. Cheben, I. Molina-Fernández, and G. Z. Mashanovich, 26, 528 (2017).

15. M. Sinobad, C. Monat, B. Luther-davies, P. Ma, S. Madden, D. J. Moss, A. Mitchell, D. Allioux, R. Orobtchouk, S. Boutami, J.-M. Hartmann, J.-M. Fedeli, and C. Grillet, Optica 5, 360 (2018).

16. J. M. Ramirez, Q. Liu, V. Vakarin, J. Frigerio, A. Ballabio, X. Le Roux, D. Bouville, L. Vivien, G. Isella, and D. Marris-Morini, Opt. Express 26, 870 (2018).

17. V. Vakarin, J. M. Ramírez, J. Frigerio, A. Ballabio, X. Le Roux, Q. Liu, D. Bouville, L. Vivien, G. Isella, and D. Marris-Morini, Opt. Lett. 42, 3482 (2017).

18. P. R. Griffiths and J. A. de Haseth, Fourier Transform Infrared Spectrometry (John Wiley \& Sons, Inc., Hoboken, NJ, USA, 2007). 